\title{
Dispersal of Triatoma infestans and other Triatominae species in the arid Chaco of Argentina - Flying, walking or passive carriage? The importance of walking females
}

\author{
Luciana Beatriz Abrahan/ ${ }^{+}$, David Eladio Gorla, Silvia Susana Catalá \\ Centro Regional de Investigaciones Científicas y Transferencia Tecnológica de La Rioja, \\ Mendoza y Entre Ríos 5301, Anillaco, La Rioja, Argentina
}

\begin{abstract}
The aim of this paper was to analyse the active dispersal of Triatoma infestans and the role of chickens as passive carriers of this insect in peridomestic areas of La Rioja, Argentina. To measure active dispersal, monthly catches were made on six consecutive nights for five months (in the warm season) using light traps (for flying insects) and sticky dispersal barriers (for walking insects). The nutritional and reproductive states of adults were evaluated. Over the course of the sampling period, a total of eight flying adults, six walking nymphs and 10 walking adults of the species T. infestans were captured, as well as specimens of Triatoma guasayana, Triatoma eratyrusiformis and Triatoma platensis. Our data demonstrate for the first time that females of $\mathrm{T}$. infestans can disperse by walking. This may be an adaptive strategy because it allows them to move with eggs and/or with good blood reserves, which are not possible when flying. All flying and walking individuals of both genders were of an appropriate physiological state that would allow for colonisation of the target habitat. However, manual inspection of 122 chickens suggests that it is unlikely that these animals passively transport $\mathrm{T}$. infestans. Finally, the dispersal activity of $\mathrm{T}$. infestans was compared with other triatomines using a dispersion index.
\end{abstract}

Key words: Triatoma infestans - dispersive behaviour - Chagas disease - walking dispersion - triatomines

More than 130 species of Triatominae (Hemiptera: Reduviidae) have been recorded from various habitats on the American continent and all have exhibited bloodsucking behaviour and the ability to transmit Trypanosoma cruzi, the flagellate that causes Chagas disease in humans. A few species of Triatominae have particular public health significance because of their close association with the human habitat and over $50 \%$ of current cases of Chagas disease have been produced by vector transmission of Triatoma infestans (Dujardin et al. 2002).

$T$. infestans lives almost exclusively in human dwellings and peridomestic habitats and has been the target of a regional elimination program, the Southern Cone Initiative, since 1991 (OMS 1991). This program has been more successful in Brazil, Chile and Uruguay than in the Chaco region of Argentina, Bolivia and Paraguay. It is believed that the persistence of $T$. infestans in the Chaco region is due to the difficulty of eliminating the vector in peridomestic buildings. These areas present complex structures that not only prevent good penetration of insecticide but also expose the chemical to climatic factors that accelerate its degradation (Schofield 1994, Gürtler et al. 2004). The persistence of vector populations instead in these habitats has led to proposals that the peridomicile, from which the insects disperse by flight, is the

Financial support: CONICET, ANCyT, FONCYT PICT (2006 878)

+ Corresponding author: labrahan@crilar-conicet.com.ar

Received 20 September 2010

Accepted 22 December 2010 origin and principal source of reinfestation of houses after an insecticide application (Schofield 1980, Carcavallo 1985, Cecere et al. 2004, Vazquez-Prokopec et al. 2004).

It has been postulated that dispersal by flight is the main colonisation strategy used by T. infestans, as it allows for displacement of around $200 \mathrm{~m}$ (Schofield et al. 1992) and more (Schweigmann et al. 1988). Nutritional (Lehane et al. 1992, McEwen \& Lehane 1993) and reproductive status (McEwen \& Lehane 1994), as well as population density (McEwen et al. 1993) and environmental conditions (Williams \& Schofield 1985, Lehane et al. 1992, Schofield et al. 1992), are known factors that modulate this activity in Triatominae. In contrast, the active dispersal of walking $T$. infestans is poorly understood. The only data available are indirect; VazquezProkopec et al. $(2004,2006)$ studied flight dispersal in the Argentine province of Santiago del Estero and captured eight fifth instar nymphs of $T$. infestans walking into sheet light traps (LT) that incidentally reached the collecting ground.

Domestic animals and humans may carry $T$. infestans in their clothes, feathers or hair, contributing to reinfestation of human domiciles from peridomestic sites. Such passive dispersal by humans is believed to have contributed greatly to the rapid geographical spread of T. infestans through the Southern Cone of Latin America (Schofield 1994).

For the current study, the Independencia department of province La Rioja (Argentina) was selected because it has the highest infestation rates within houses (45.1\%) and in peridomestic structures (57.3\%), according to a previous assessment by the Programa Chagas La Rioja (ChLaR) in April 2006, before their intervention efforts 
(Porcasi et al. 2007). Our aim in the present study was to analyse the active dispersal of $T$. infestans (flying and walking) and the possible role of chickens as passive carriers of the insect in peridomestic areas of La Rioja. This is the first study of this type that is designed specifically to quantify the dispersal of walking $T$. infestans and passive carriage of the insect by chickens.

\section{SUBJECTS, MATERIALS AND METHODS}

Study area - The rural houses of the Independencia department did not receive vector control interventions between 1991-2006. From October-December of 2006, the ChLaR carried out an Indoor Residual Spraying intervention using suspension concentrate betacypermethrin at $50 \mathrm{mg} / \mathrm{m}^{2}$ that was applied with manual sprayers with Schmitt 8002 fan nozzles. Peridomestic structures were not sprayed, but dogs, goats and chickens were treated with pour-on veterinary formulations of insecticides currently used for domestic animals (dogs were treated with $5 \mathrm{cc}$ of $1 \%$ fipronil, whereas goats and chickens were treated with $5 \mathrm{cc}$ and $1 \mathrm{cc}$ of $6 \%$ cypermethrin, respectively). Preliminary data from active searches lasting 30 min using $0.2 \%$ tetramethrin as a dislodging agent showed that in January, April and October 2007, T. infestans was not detected within houses, but numerous colonies were detected in goat corrals and chicken coops.

The selection of the rural houses for the present study was based on the presence of abundant peridomestic $T$. infestans populations and the owners' cooperation in allowing access to their homes. Within the research area, two zones [east (E) and west (W)] were considered for the study. This was based on a previous analysis that showed different $T$. infestans population structures and suggested a different degree of individual exchange in these areas (Hernández et al. 2010).

The study was carried out in six rural houses: three in Patquía Viejo [S30,171028 W66,955778, 569 meters above sea level (masl)], two in Salinas de Busto (S30,2638 W67,606367, 1128 masl) and one in La Torre (S30,20346 W67,60602, 1182 masl); all houses were in the Independencia department and within the Arid Chaco region. Salinas de Busto and La Torre are $10 \mathrm{~km}$ apart and are situated on the $\mathrm{W}$ zone of the department, whereas Patquía Viejo is located on the E zone of the department, $85 \mathrm{~km}$ from Salinas de Busto and La Torre (Fig. 1).

Cactaceous plants, grass and scrub constitute the normal habitat for other silvatic triatomine species that occasionally fly to domiciles.

The most frequent peridomestic structures in the study area are chicken coops and goat corrals. The chicken coops are commonly constructed of wood, sticks, bricks and/or wire around the perimeter. The roof may have branches, wood, leather, cardboard and/or plastic. Occasionally, chickens and other domestic birds sleep on tree branches, but brooding hens are kept in small shelters built of adobe or bricks, with cardboard, fabric, plastic or zinc roofs. Chicken coops are 10-20 m from the house. Goat corrals usually have a more homogeneous construction, with interlaced sticks or tree branches as walls and a roofed area for calves. The distance between the house and goat corrals is normally about $100 \mathrm{~m}$ and between both peridomestic structures, there is usually less than $100 \mathrm{~m}$.
Before the treatment in October 2006, a 30 min active search in each ecotope by technicians of the ChLaR revealed 10-15 insects per goat corral and 4-22 insects per chicken coop.

Experimental design - Fieldwork was carried out during the five months of the warm season of 2008/2009 (November-March). Flying insects were captured using LT and walking specimens were captured using sticky dispersal barriers (DB). The LT and DB were installed monthly in the peridomestic area of the selected domiciles. Monthly catches were carried out over six consecutive nights ( 3 nights in each zone, $\mathrm{E}$ and $\mathrm{W}$ ), giving a total of 30 trap-nights.

Capture of flying T. infestans - Each night, three LT were installed in each domicile (9 LT per night), between $10-30 \mathrm{~m}$ from the nearest habitat and up to $50 \mathrm{~m}$ from the farthest. Light trapping was performed from 7:30 pm7:00 am. The LT consists of a cross of aluminium panels with four battery-powered white light-emitting diode lights. The LT is supported on four aluminium legs that are $1.3 \mathrm{~m}$ tall to prevent bugs from climbing into the trap. When a flying insect hits the aluminium panels, it falls into a cloth bag, from which it can be collected manually (Fig. 2A). Each LT was positioned with a Garmin Legend GPS to maintain the same location every night. Fig. 3 shows the localisation of LTs in a domicile of the E zone.

Capture of walking T. infestans - Three chicken coops and two goat corrals in the E zone and two chicken coops and three goat corrals in the $\mathrm{W}$ zone were studied. DB were placed surrounding the habitat to collect the walking specimens, $20-30 \mathrm{~cm}$ outside the external walls. The dispersal barrier is a sticky trap placed on the ground around a corral or a chicken coop. It consists of a foam rubber strip $4.5 \mathrm{~cm}$ wide with double-sided adhesive tape $5 \mathrm{~cm}$ wide on the upper surface (Fig. 2B). The entire perimeter (average $5 \mathrm{~m}$ ) of the chicken coops was surrounded with a DB, but for goat corrals, only the kids' area was selected (average $11.5 \mathrm{~m}$ ) because it usually has the highest density of triatomines. The total capture effort with DB used $375 \mathrm{~m}$ of sticky traps for chicken coops and $862 \mathrm{~m}$ for goat corrals.

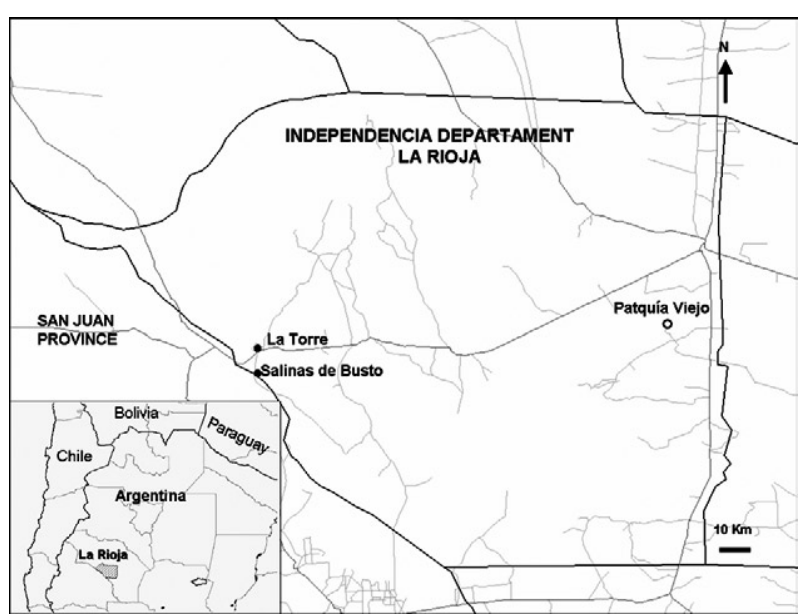

Fig. 1: study area in the Independencia department of La Rioja, Argentina. 


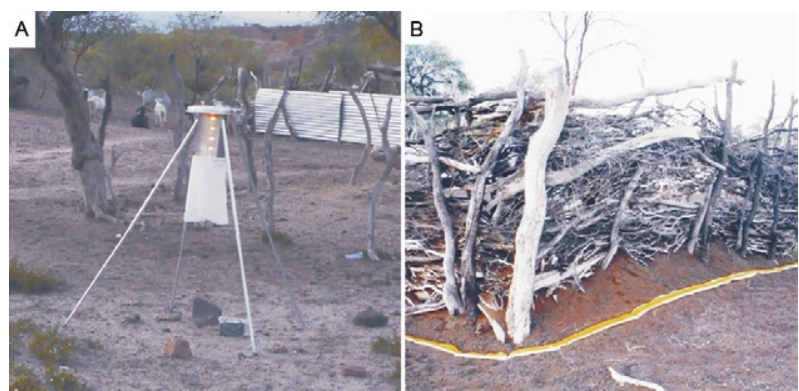

Fig. 2A: light trap; B: dispersion barrier mounted around a goat corral.

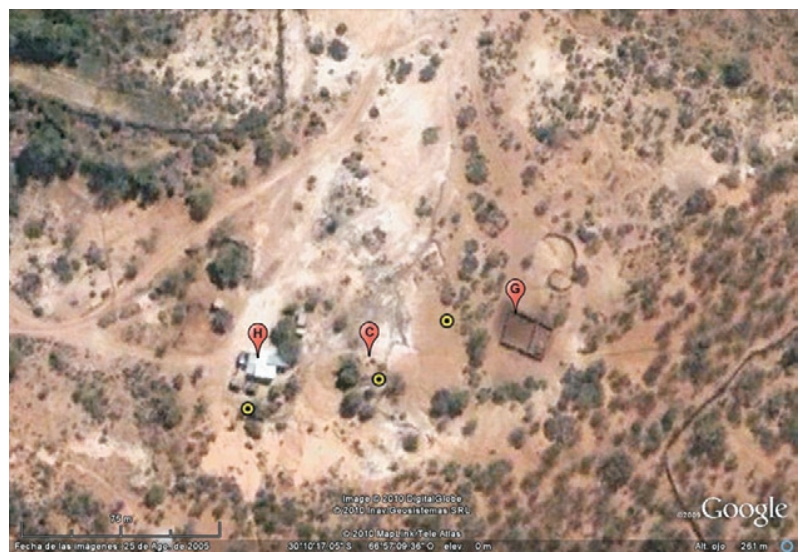

Fig. 3: localization of light traps in a domicile from Patquía Viejo, Independencia department of La Rioja, Argentina. H: house; C: chicken coop; G: goat corral.

Dispersion index (DI) - To enable comparison between species, we used a DI, which indicates the ease of capture of each species. The number of walking and flying individuals of each species captured was divided by the number of nights the traps were set up (DI = number of captured individuals/number of trapping nights).

Insects - Captured specimens were maintained in plastic jars identifying house of origin, habitat, locality, date and trap type used. Insects were kept alive at $10^{\circ} \mathrm{C}$ in a portable refrigerator for transportation and once in the laboratory, species and stages were determined (Lent \& Wygodzinsky 1979, Brewer et al. 1981, 1983).

Nutritional status (W/L) - Body weight (TR) of adult T. infestans was determined with an analytical scale (Sartorius BP $221 \mathrm{~S}$ ) accurate to $0.1 \mathrm{mg}$. Body length was measured from the clypeus to the abdominal tip using a hand-held calliper. These measurements were used to calculate the $\mathrm{W} / \mathrm{L}$ ratio, which is used by many authors as an indicator of flight dispersal probability (Lehane \& Schofield 1982, Lehane et al. 1992, Ceballos et al. 2005, Gurevitz et al. 2006).

Blood reserve - The shape and volume of the anterior midgut (promesenteron) of adult specimens was used to classify the insects as starved or with scarce, good or large blood reserves (Montenegro 1983). This qualitative technique is useful in females because it avoids the distortion produced by the presence of eggs in the oviduct that is seen when estimating the $\mathrm{W} / \mathrm{L}$.

Thoracic muscle status - The proportion of thoracic muscle mass to TR was estimated using the index proposed by Marden (2000) for flying insects and by Gurevitz et al. (2007) for triatomines (flight muscle ratio $=$ flight muscle mass/total body mass). However, to avoid the error derived from incomplete muscle mass extraction, the entire thorax, minus the pronotum, was weighed on an analytical balance. In addition, the consistency (solid or liquid) and colour (pink or white) of muscles were recorded.

Reproductive status - In females, the state of the spermatheca (empty: virgin female, full: fertilised) and the number of chorionated eggs present in the oviducts were examined. In males, the state of the seminal vesicles, efferent duct and accessory glands were checked.

The quantitative and qualitative analysis of these variables aided in understanding the physiological state of $T$. infestans and in estimating the value of these insects as potential colonisers and dispersants.

Infection by T. cruzi - All triatomines were examined microscopically for $T$. cruzi infection at $400 \mathrm{X}$ magnification.

Weather variables - A weather station (Weather Monitor II, Davis Instruments) was installed at each zone during the three-day trapping interval to monitor temperature, relative humidity, wind speed and rainfall at half-hour intervals. The mean, maximum and minimum values of these variables were used to compare days with and without dispersal.

Chickens as passive carriers - Between November 2008-March 2009, a total of 122 chickens were tested by searching for different stages of $T$. infestans. The legs and wings of the chickens were tied and their plumage was sprayed with $0.2 \%$ tetramethrin as a dislodging agent (Space 0.2). After $5 \mathrm{~min}$, the skin and feathers of the chickens were intensively examined while the animal remained prone on white plastic.

Statistical analysis - Means and standard deviations were obtained for the variables of thoracic muscle weight, reproductive and $\mathrm{W} / \mathrm{L}$. The Levene test was used to check variance homogeneity. When the variance was heterogeneous, we used the Kruskal-Wallis non-parametric test. The variables with homogeneity of variance were analysed by ANOVA. For post-hoc comparisons, we used the Fisher LSD test (Statistica, Statsoft Inc version 7.1 2006), whereas the Fisher exact test (Infostat 2004, Grupo InfoStat, FCA, Universidad Nacional de Córdoba, Argentina) was used when comparing proportions.

\section{RESULTS}

Active flight dispersion - A total of eight T. infestans adults were collected over 270 trap-nights between November 2008-March 2009 in both zones. Most insects $(75 \%, 6 / 8)$ were captured in January 2009 . Other species were also captured: 21 Triatoma guasayana, eight Triatoma eratyrusiformis and two Triatoma platensis (Table I). 
Active walking dispersion - A total of six adults and three nymphs of $T$. infestans were collected on DB in goat corrals and four adults and three nymphs were trapped on DB in chicken coops.

The highest number of specimens was captured in January 2009. Table II contains details of captured $T$. infestans classified by development stage and habitat. We observed that $62.5 \%(5 / 8)$ of walking females were leaving the habitat, whereas the other $37.5 \%$ (3/8) were entering the habitat.

Other species were also captured: in the E zone, four specimens ( 2 females and 2 nymphs) of T. eratyrusiformis and two adults (1 female and 1 male) of T. guasayana were collected. In the $\mathrm{W}$ zone, a T. eratyrusiformis male and a T. guasayana female were collected by DB.

$D I$ - For all species collected by LT, males showed a higher DI than females, except in T. guasayana. When comparing males of different species, T. eratyrusiformis and T. guasayana had higher proportions of flying dispersion than T. infestans (Fig. 4A) and T. platensis.

For the three species collected by DB, females and nymphs showed a higher DI than males, especially in T. infestans, which had a higher proportion of walking dispersion than the other species (Fig. 4B). For females, $T$. infestans showed a higher proportion of walking dispersion than $T$. guasayana $(\mathrm{p}=0.004)$.

$W / L$ - In general, the insects were captured with W/L $<8 \mathrm{mg} / \mathrm{mm}$, but these values were not frequent in insects captured in the DB traps, which had ratios $>8 \mathrm{mg} /$ $\mathrm{mm}$ (Table III). Flying and walking males did not differ significantly in their nutritional status, as evaluated by W/L. In contrast, females collected by LT showed lower W/L than those collected by DB in chicken coops and goat corrals ( $p<0.044$ and $p<0.015$, respectively) (Fig. $5)$. No significant statistical difference in W/L was observed in females collected by DB in chicken coops and goat corrals $(\mathrm{p}>0.05)$.

Blood reserve - The estimated blood reserve indicated that $5 / 8(62.5 \%)$ of the females collected by DB were starved, whereas $37.5 \%$ had good or large blood reserves. All females (3/3) collected by LT were starved. In contrast, $80 \%(4 / 5)$ of males collected by LT were starved and $20 \%(1 / 5)$ had scarce blood reserves, whereas $50 \%$ of males collected by DB were starved and the other $50 \%$ had scarce blood reserves.

Thoracic muscle status - The weight of the thoracic muscle relative to TR did not show differences between specimens of the same sex collected by either method (Table III). All specimens had solid, well-developed and mostly pink muscles. The observed minimum TR value for flying males was $22.09 \%$ and for females was $19.5 \%$.

Reproductive status - Migrant males captured by either method had accessory glands filled with secretory fluid and seminal vesicles and efferent ducts with abundant sperm.

Ninety-one percent (10/11) of migrant females caught by either method were fertilised. One virgin female without eggs was collected on a DB in a chicken coop. Although the number of chorionated eggs per mated female did not differ statistically between capture methods, it was highly variable (DB in chicken coops: $1,21,37$; DB in corrals: 0, 5, 5, 13; LT: 2, 7, 7).

Relationship between blood reserve and number of chorionated eggs in T. infestans females - All females collected by LT were starved and had between 1-13 eggs, whereas walking females transported either many eggs in their oviducts (up to 35) or a good blood reserve in their promesenteron (Fig. 6).

Infection by T. cruzi - None of the captured insects were infected with $T$. cruzi.

Weather variables - During the study period, the weather conditions appeared optimal for flight dispersal, according to the conditions described by Lehane et al. (1992) and Schofield et al. (1992), except for the first two days of trapping in December, when there was

\section{TABLE I}

Number of Triatoma infestans and other species collected by light traps between November 2008-March 2009 in the Independencia department, La Rioja, Argentina

\begin{tabular}{lcccccccc}
\hline & \multicolumn{3}{c}{$\begin{array}{c}\text { Triatoma } \\
\text { infestans }\end{array}$} & \multicolumn{2}{c}{ Triatoma } & \multicolumn{2}{c}{ Triatoma } & \multicolumn{2}{c}{ Triatoma } \\
gunth & F & M & F & M & F & M & F & M \\
\hline Nov & 0 & 0 & 10 & 5 & 0 & 5 & 0 & 0 \\
Dec & 0 & 1 & 1 & 1 & 1 & 0 & 1 & 0 \\
Jan & 2 & 4 & 2 & 2 & 1 & 1 & 0 & 0 \\
Feb & 0 & 0 & 0 & 0 & 0 & 0 & 0 & 0 \\
Mar & 1 & 0 & 0 & 0 & 0 & 0 & 1 & 0 \\
\hline Total & 3 & 5 & 13 & 8 & 2 & 6 & 2 & 0 \\
\hline
\end{tabular}

F: females; M: males.

\section{TABLE II}

Number of Triatoma infestans collected by dispersion barriers (walking insects) between November 2008-March 2009, in Independencia Department, La Rioja, Argentina

Dispersion barriers

\begin{tabular}{lcccccccc} 
& \multicolumn{3}{c}{ Goat corrals } & \multicolumn{4}{c}{ Chicken coops } \\
\cline { 2 - 9 } Month & F & M & N & Total & F & M & N & Total \\
\hline Nov & 1 & 0 & 0 & 1 & 0 & 0 & 0 & 0 \\
Dec & 1 & 0 & $1 \mathrm{~N} 1$ & 2 & 1 & 0 & $1 \mathrm{~N} 1$ & 2 \\
Jan & 2 & 1 & 0 & 3 & 1 & 0 & $1 \mathrm{~N} 3$ & 2 \\
Feb & 0 & 0 & 0 & 0 & 1 & 0 & $1 \mathrm{~N} 3$ & 2 \\
Mar & 0 & 1 & $1 \mathrm{~N} 3,1 \mathrm{~N} 4$ & 3 & 1 & 0 & 0 & 1 \\
\hline Total & 4 & 2 & 3 & 9 & 4 & 0 & 3 & 7
\end{tabular}

F: females; M: males; N: nymphs. 

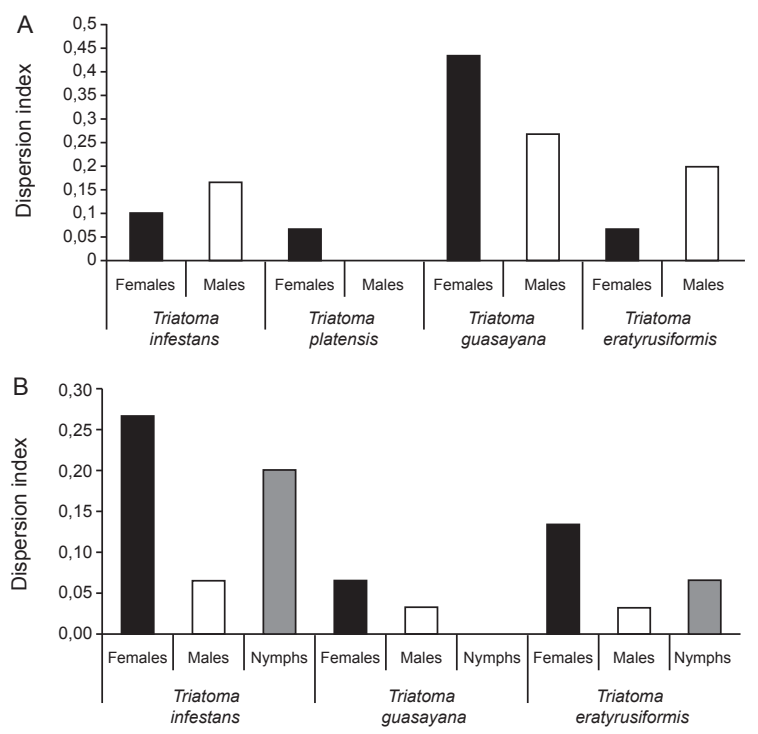

Fig. 4: dispersion index for Triatoma infestans and others species during the hot season (November-March 2008/2009) in Los Llanos, La Rioja, Argentina. A: flying insects collected by light trap; B: walking insects collected by dispersion barriers.

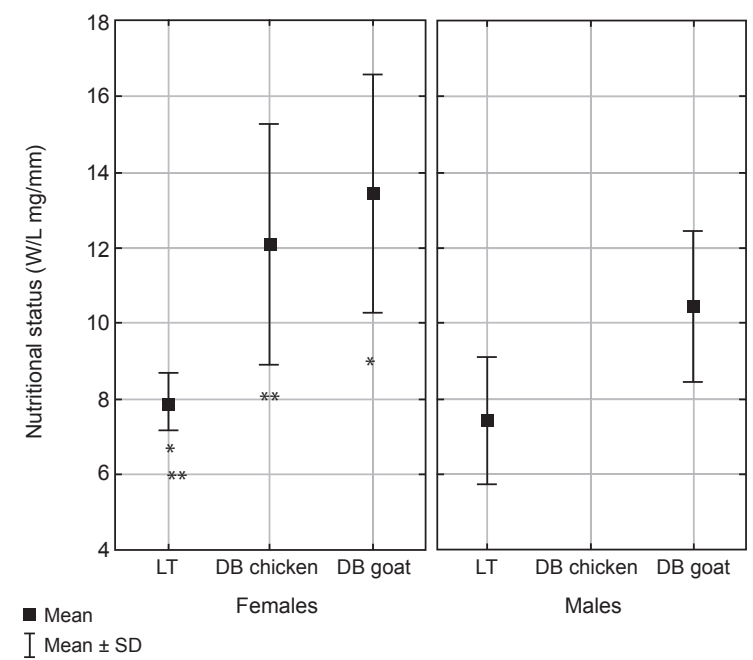

Fig. 5: nutritional status [weight(W)/length(L)] of Triatoma infestans according to adult sex and capture method. No males were collected in dispersion barriers at chicken coops. SD: standard deviation; *: significant difference between females collected by light trap (LT) and dispersion barrier (DB) in goat corrals; **: significant difference between females collected by LT and DB in chicken coops.

TABLE III

Characteristics of adult Triatoma infestans captured with light traps (LT) and dispersion barriers (DB)

\begin{tabular}{|c|c|c|c|c|c|c|}
\hline Capture method & $\begin{array}{l}\text { Sex } \\
\text { (n) }\end{array}$ & $\begin{array}{c}\text { Body } \\
\text { weight }\end{array}$ & $\begin{array}{l}\text { Body } \\
\text { length }\end{array}$ & Weight/length & $\begin{array}{c}\text { Thoracic } \\
\text { muscle mass }\end{array}$ & $\begin{array}{c}\text { Thoracic } \\
\text { muscle ratio }\end{array}$ \\
\hline LT & $\begin{array}{l}\text { Females } \\
\text { (3) }\end{array}$ & $206.33(19.88)^{a}$ & $26.06(0.99)$ & $7.93(0.76)^{a}$ & $49.80(6.92)^{b}$ & 24.39 (4.90) \\
\hline LT & $\begin{array}{l}\text { Males } \\
\text { (5) }\end{array}$ & $192.14(42.8)$ & $25.84(0.98)$ & 7.44 (1.68) & 47.50 (7.89) & $25.12(3.39)$ \\
\hline DB & $\begin{array}{c}\text { Females } \\
\text { (8) }\end{array}$ & $347.51(82.22)^{a}$ & $27.28(0.67)$ & $12.74(3.02)^{a}$ & $61.45(8.02)^{b}$ & $18.56(5.10)$ \\
\hline DB & $\begin{array}{l}\text { Males } \\
\text { (2) }\end{array}$ & $271(66.04)$ & $25.81(1.40)$ & 10.45 (1.99) & $57.00(5.66)$ & $21.41(3.13)$ \\
\hline
\end{tabular}

$a$ : significant differences $\mathrm{p}<0.04 ; b$ : significant differences $\mathrm{p}<0.007$. Mean of body weight (mg), body length (mm), body weight/ length $(\mathrm{mg} / \mathrm{mm})$, thoracic muscle mass $(\mathrm{mg})$ and thoracic muscle ratio $(\mathrm{mg} / \mathrm{mg})$ according to adult sex and capture method.

light rain and no dispersive movements were recorded. The only weather variable that showed significant differences between dispersal and non-dispersal days was relative humidity $(\mathrm{p}<0.007)$. Dispersal days were characterised by a lower maximum relative humidity $(65 \%$ $\pm 10.56 \%$ ) compared to days in which dispersal did not occur $(81.33 \% \pm 16.97 \%)$.

Chickens as passive carriers - No specimens of $T$. infestans were found on the 122 chickens (approximately $50 \%$ of total) manually checked during the sampling period. The search method seemed appropriate for finding any stage of $T$. infestans because we were always able to confirm the presence of lice (order Mallophaga) with a body length between 1.5-3.5 $\mathrm{mm}$ on the same chickens.

\section{DISCUSSION}

Dispersal of Triatominae among and between habitats is an important factor influencing the long-term success of vector-control intervention due to the fact that dispersants can re-colonise treated ecotopes (Schofield $\&$ Matthews 1985). The main mechanisms determining T. infestans reinfestation of rural communities appear to be active flight from peridomestic residual foci and, with lower frequency, passive transport by humans from nearby infested communities (OMS 2002). There are no data on walking dispersal of $T$. infestans or on the role of domestic animals in passive transport. Both issues are of paramount importance in vector control and are discussed in the present work. Moreover, for the first time, 


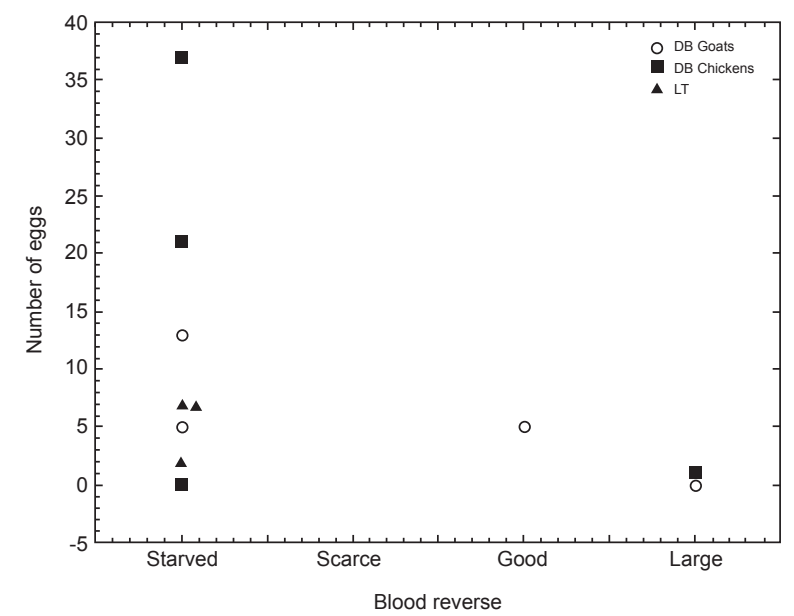

Fig. 6: relationship between the blood reserve and number of chorionated eggs in females of Triatoma infestans captured by light trap (LT) and dispersion barrier (DB).

temporal tracing of dispersants was carried out over five consecutive months of the warm season, allowing for the measurement of monthly variation in catches.

Active flight dispersion - It has been suggested that low W/L $(<8 \mathrm{mg} / \mathrm{mm})$ is the trigger for flight dispersal in adult T. infestans (Schofield 1980, 1985, Carcavallo 1985, Schofield et al. 1992, McEwen \& Lehane 1993), especially in individuals from the peridomicile (Cecere et al. 2004), which are considered the main reinfestation sources of human dwellings. In this study, the average W/L of flying $T$. infestans was $8 \mathrm{mg} / \mathrm{mm}$ (starved) in both sexes, supporting the hypothesis that the need for food is an important factor in flight initiation (Lehane \& Schofield 1982, Lehane et al. 1992). Observations of adult Rhodnius prolixus showed that in the absence of food, nutritional reserves seem to be directed toward the development of flight muscles (Gringorten \& Friend 1979). Our results support these observations because in both $T$. infestans sexes, we found well-developed flight muscles despite limited food reserves. These data also suggest that the probability of flight initiation may be the same for both adult sexes.

Some authors have noted sexual differences in flight initiation. In laboratory experiments, Gurevitz et al. (2007) found dimorphism in muscle growth in adults, observing an absence of flight muscles more frequently in males and, therefore, a potentially lower dispersive capacity. However, in field experiments with laboratory T. infestans, the number of females dispersing by flight was higher relative to males (Canale \& Carcavallo 1985, Schofield et al. 1992, Gurevitz et al. 2006, Minoli \& Lazzari 2006). The results presented here would indicate that $T$. infestans males fly more frequently than females, coinciding with the results of Vazquez-Prokopec et al. (2004) and Ceballos et al. (2005).

The DI proposed in this study allowed for comparison of the flight dispersal activity of T. infestans with other species. We observed a low DI for T. infestans, similar to
T. platensis and T. eratyrusiformis. In contrast, T. guasayana was the species with the highest average number of flying individuals. Even though this species does not normally colonise human dwellings, adult bugs may often invade them temporarily. In the Chaco region, $T$. guasayana, which inhabits a wide variety of ecotopes (Barretto 1971, Carcavallo \& Martinez 1985), has a high potential for night flight dispersal during the hot dry months (August-November) (Wisnivesky-Colli et al. 1993, Noireau et al. 1999).

The DI we obtained for T. infestans caught in LT was 0.0296, whereas Vazquez-Prokopec et al. (2004) found a dispersal index of 0.1875 . That is, the number of individuals captured in Los Llanos Riojanos, La Rioja was lower than the number captured in Santiago del Estero. This difference can probably be attributed to differences in the degree of infestation of domestic areas and environmental factors, as well as the different methodologies used in the two studies.

Active dispersal is usually associated with searching for food and a mate (Schofield 1994). In our study, flying $T$. infestans females were always starved, fertilised and with some chorionated eggs in their oviducts (Fig. 6). Males had accessory glands with secretory fluid and abundant sperm in the seminal vesicles and efferent ducts. These results indicate that at the moment of dispersal, adults are reproductively prepared to colonise the new habitat. However, because the value as colonisers is different for each sex, it is important to elucidate sex differences in the dispersive behaviour. Only fertilised females can initiate a new colony alone. Similarly, virgin females that disperse may successfully colonise only if they find a male in the new habitat. In contrast, a fertilised female can generate a colony by herself if she carries eggs and/or enough food to support their development; these are the individuals that represent a true risk for humans as potential colonisers of human dwellings.

Active walking dispersion - This type of dispersal has been so far unexplored in T. infestans and little is known about the dispersal of other species. VazquezProkopec et al. $(2004,2006)$ obtained indirect information when they captured eight fifth-instar nymphs in sheet-like LT for collecting flying individuals. Their data suggested that $T$. infestans have low mobility during nymphal development and, consequently, the dispersal of this species would occur mainly as flying adults. Our work demonstrates for the first time the capability for walking dispersal of adults and nymphs of T. infestans caught around goat corrals and chicken coops.

The average $\mathrm{W} / \mathrm{L}$ of adult walkers was greater than $10 \mathrm{mg} / \mathrm{mm}$. Collected males and females had excellent reproductive status, similar to the flying adults. Although females generally had low blood reserves, a sizable quantity of eggs was almost always found in their oviducts and this was more obvious in those coming from chicken coops. Some females $(3 / 10,30 \%)$ had a good blood reserve in the mid-gut and a small number of chorionated eggs (Fig. 6) which may ensure egg production proportional to the blood present in their mid-gut (Montenegro 1989). 
Walking females were captured more frequently than flying ones; however, this could result from either different trapping methodologies or a true dispersive difference. We cannot determine what the source habitat of the migrants is, but genetic analyses are in process to determine it.

The results raise the question of what generates female dispersal when it is not related to foraging. Ceballos Perazzi (1985) showed that there is a "group effect" that alters oviposition in fertilised females of $T$. infestans. In that experiment, the females that grouped with conspecifics of the same sex had lower fecundity than isolated females or females grouped with males of the same species. This effect could be due to the release of pheromones that decrease fecundity in the presence of other females. This phenomenon has been previously documented in other insects and arthropods (Bruce 1970, Khalil 1984). In the present case, it seems reasonable to consider that in habitats with this type of intraspecific competition, females would choose to migrate despite the fact that food availability is not an issue. Relative to other species, $T$. infestans females showed a predisposition to disperse by walking when compared to T. guasayana females, but no difference was detected when compared with females of T. eratyrusiformis.

These results suggest that dispersal by walking in $T$. infestans females may be an adaptive strategy that could facilitate achieving successful colonisation in the domestic habitat because, unlike flight locomotion, walking allows movement with many eggs in the oviducts and/or with good blood reserves.

Dispersion, seasonality and weather variables - Temperatures below $23^{\circ} \mathrm{C}$, rain and winds of more than $5 \mathrm{~km} / \mathrm{h}$ appear to have a negative effect on dispersal (Gurevitz et al. 2006). In contrast, weather conditions seemed ideal for dispersal during the sampling period in Los Llanos. However, we did observe that active flight and walking occurred when the maximum average relative humidity was below 65\%. According to Curto de Casas \& Carcavallo (1995), low relative humidity would stimulate an increase in feeding frequency to prevent dehydration and would consequently promote a search for food. In our study, the highest number of dispersing $T$. infestans were captured in January (mid summer), whereas VazquezProkopec et al. (2006) and Ceballos et al. (2005) captured the most flying individuals in March (late summer).

Passive dispersal - Passive dispersal is considered one of the most frequent ways of spreading for triatomines over large areas. Nymphs, eggs and adults may be transported in or on human clothes, mammalian hair or bird feathers (Forattini et al. 1971, Lent \& Wygodzinsky 1979). Chickens often enter houses and sleep in the bedrooms, allowing for the growth of large populations of T. infestans (Gürtler et al. 1996, 1997, Cecere et al. 1997, Catalá et al. 2004); chickens have also been suspected of being passive carriers of bugs. In our study however, no T. infestans nymphs or adults or other triatomines were found in the feathers of chickens. This suggests that in this region it is unlikely that chickens transport $T$. infestans passively and, therefore, do not likely contribute to the reinfestation of human dwellings.
Our study suggests that the exchange rate of individuals between different domestic structures is low, and thus, domiciliary reinfestation would be very slow or even absent in the study area. This is in agreement with the house infestation rates detected by our group and ChLaR (2009, unpublished observations), reporting that after three years of insecticide application in the same area, infestation of human dwellings was very low despite the fact that peridomestic structures continued to be infested. The findings of our study suggest that a better understanding of the risk that peridomestic populations of T. infestans represent for the re-infestation of human dwellings in the region of Los Llanos is needed.

\section{ACKNOWLEDGEMENTS}

To J Paliza, N Folguera, I Amellotti, L Hernández and M Sandoval, for contributing in field and/or laboratory work, to F Noireau, A Carbajal and C Macedo, for the provision of double-side adhesive tape, to I Amelotti, for her helpful comments, to J Di Rienzo, for his statistic assistance, and to CJ Schofield and V Valentinuzzi, for providing language help.

\section{REFERENCES}

Barretto MP 1971. Estudos sôbre reservatórios e vetores silvestres do Trypanosoma cruzi. XLV: inquérito preliminar sôbre triatomíneos silvestres no Sul do estado de Mato Grosso, Brasil (Hemiptera: Reduviidae). Rev Bras Biol 31: 225-233.

Brewer M, Garay M, Gorla D, Murua F, Favot R 1981. Caracterización de los estadios ninfales del genero Triatoma Laporte 1833. I. Triatoma infestans Klug, 1834 (Hemiptera: Reduviidae). Rev Soc Entomol Argent 40: 91-102.

Brewer M, Gorla D, Garay ME 1983. Caracterización de los estadios ninfales del género Triatoma Laporte, 1833. III Analisis biométrico descriptivo de Triatoma infestans Klug, 1834; Triatoma platensis Neiva, 1913; Triatoma delpontei Romaña y Avalos, 1947 y Triatoma sordida (Stal) 1859 (Hemiptera: Reduviidae). Rev Soc Entomol Argent 42: 219-241.

Bruce HM 1970. Pheromones. Br Med Bull 26: 10-13.

Canale DM, Carcavallo RU 1985. Triatoma infestans (Klug), In RU Carcavallo, JE Rabinovich, RJ Tonn (eds.), Factores biológicos y ecológicos en la enfermedad de Chagas, vol. I, Ministerio de Salud y Acción Social de Argentina, Buenos Aires, p. 237-250.

Carcavallo RU 1985. Técnicas de estudio de triatominos en ambiente silvestre. In RU Carcavallo, JE Rabinovich, JE Tonn (eds.), Factores biológicos y ecológicos en la enfermedad de Chagas, vol. I, Ministerio de Salud y Acción Social de Argentina, Buenos Aires, p. 49-52.

Carcavallo RU, Martinez A 1985. Biología, ecología y distribución geográfica de los triatominos americanos (excepto $R$. prolixus, P. megistus, T. dimidiata y T. infestans). In RU Carcavallo, JE Rabinovich, RJ Tonn (eds.), Factores biológicos y ecológicos en la enfermedad de Chagas, vol. I, Ministerio de Salud y Acción Social de Argentina, Buenos Aires, p. 149-208.

Catalá SS, Crocco LB, Muñoz A, Morales G, Paulone I, Giraldez E, Candioti C, Ripol C 2004. Entomological aspects of Chagas' disease transmission in the domestic habitat, Argentina. Rev Saude Publica 38: 216-222.

Ceballos LA, Vazquez-Prokopec GM, Cecere MC, Marcet PL, Gürtler RE 2005. Feeding rates, nutritional status and flight dispersal potential of peridomestic populations of Triatoma infestans in rural northwestern Argentina. Acta Trop 95: 149-159. 
Ceballos Perazzi NS 1985. Comunicación química en el reino animal. Efecto del grupo en la oviposición de hembras de Triatoma infestans Klug, 1834 (Hemiptera: Reduviidae), Seminario II, Universidad Nacional de Córdoba, Argentina, 10 pp.

Cecere MC, Gürtler RE, Canale D, Chuit R, Cohen JE 1997. The role of the peridomiciliary area in the elimination of Triatoma infestans from rural Argentina communities. Rev Panam Salud Publica 1: 273-279.

Cecere MC, Vazquez-Prokopec GM, Gürtler RE, Kitron U 2004. Spatiotemporal analysis of reinfestation by Triatoma infestans (Hemiptera: Reduviidae) following insecticide spraying in a rural community in northwestern Argentina. Am J Trop Med Hyg 71: 803-810.

Curto de Casas SI, Carcavallo RU 1995. Climate change and vectorborne diseases distribution. Soc Sci Med 40: 1437-1440.

Dujardin JP, Schofield JC, Panzera F 2002. Los vectores de la enfermedad de Chagas, Sér 25, Académie Royale des Sciences d'Outre Mer, Classe des Sciences Naturelles et Médicales, p. 189.

Forattini OP, Rocha e Silva EO, Ferreira OA, Rabello EX, Pattoli DG 1971. Aspectos ecológicos da tripanossomose americana. III. Dispersão local de triatomíneos, com especial referência ao Triatoma sordida. Rev Saude Publica 5: 193-205.

Gringorten JL, Friend WG 1979. Tissue development in Rhodnius prolixus (Hemiptera: Reduviidae): dry weight changes in fed and unfed post-ecdysial males. Can Entomol 11: 735-740.

Gurevitz JM, Ceballos LA, Kitron U, Gürtler RE 2006. Flight initiation of Triatoma infestans (Hemiptera: Reduviidae) under natural climatic conditions. J Med Entomol 43: 143-150.

Gurevitz JM, Kitron U, Gürtler RE 2007. Flight muscle dimorphism and heterogeneity in flight initiation of field-collected Triatoma infestans (Hemiptera: Reduviidae). J Med Entomol 44: 186-191.

Gürtler RE, Canale DM, Spillmann C, Stariolo R, Salomón OD, Blanco S, Segura EL 2004. Effectiveness of residual spraying of peridomestic ecotopes with deltamethrin and permethrin on Triatoma infestans in rural western Argentina: a district-wide randomized trial. Bull World Health Organ 82: 196-205.

Gürtler RE, Cecere MC, Vazquez DP, Chuit R, Cohen JE 1996. Hostfeeding patterns of domiciliary Triatoma infestans (Hemiptera: Reduviidae) in northwest Argentina: seasonal and instar variation. J Med Entomol 33: 15-26.

Gürtler RE, Cohen JE, Cecere MC, Chuit R 1997. Shifting host choices of the vector of Chagas disease Triatoma infestans in relation to the availability of hosts in houses in north-west Argentina. $J$ Appl Ecol 34: 699-715.

Hernández ML, Abrahan LB, Dujardin JP, Gorla DE, Catalá SS 2010. Phenotypic variability and population structure of peridomestic Triatoma infestans in rural areas of the arid Chaco (western Argentina): spatial influence of macro- and microhabitats. Vector Borne Zoonotic Dis: doi:10.1089/vbz.2009.0253.

Khalil GM 1984. Fecundity-reducing pheromone in Argas (Persicargas) arboreus (Ixodoidea: Argasidae). Parasitology 88: 395-402.

Lehane MJ, McEwen PK, Whitaker CJ, Schofield CJ 1992. The role of temperature and nutritional status in flight initiation by Triatoma infestans. Acta Trop 52: 27-38.

Lehane MJ, Schofield CJ 1982. Flight initiation in Triatoma infestans (Klug) (Hemiptera: Reduviidae). Bull Entomol Res 72: 497-510.

Lent H, Wygodzinsky P 1979. Revision of the Triatominae (Hemiptera: Reduviidae) and their significance as vectors of Chagas disease. Bull Am Museum Nat Hist 163: 127-520.

Marden JH 2000. Variability in the size, composition and function of insect flight muscles. Annu Rev Physiol 62: 157-178.
McEwen PK, Lehane MJ 1993. Factors influencing flight initiation in the triatomine bug Triatoma sordida (Hemiptera: Reduviidae). Insect Sci Appl 14: 461-464.

McEwen PK, Lehane MJ 1994. Relationships between flight initiation and oviposition in Triatoma infestans (Klug) (Hemiptera: Reduviidae). J Appl Entomol 117: 217-223.

McEwen PK, Lehane MJ, Whitaker CJ 1993. The effect of adult population density on flight initiation in Triatoma infestans (Klug) (Hemiptera: Reduviidae). J Appl Entomol 116: 321-325.

Minoli SA, Lazzari CR 2006. Take-off activity and orientation of triatomines (Heteroptera: Reduviidae) in relation to the presence of artificial lights. Acta Trop 97: 324-330.

Montenegro S 1983. Determinación de las reservas alimenticias en Triatoma infestans Klug, 1834 (Hemiptera: Reduviidae) en base a caracteres externos. I. Adultos. Physis (Buenos Aires) 41: 159-167.

Montenegro SSC 1989. Relaciones entre consumo de sangre y ovogénesis en Triatoma infestans Klug, 1834 (Hemiptera: Reduviidae). Chagas 5: 3-10.

Noireau F, Gutierrez T, Flores R, Brenière F, Bosseno MF, Wisnivesky-Colli C 1999. Ecogenetics of Triatoma sordida and Triatoma guasayana (Hemiptera: Reduviidae) in the Bolivian Chaco. Mem Inst Oswaldo Cruz 94: 451-457.

OMS - Organización Mundial de la Salud 1991. Encuentro latinoamericano sobre "sistemas de vigilancia para evaluar el impacto de los programas de control de la enfermedad de Chagas," Córdoba, 25-29 November, 1991, OMS, Geneva, TDR/CHA/EVA 91.3.

OMS - Organización Mundial de la Salud 2002. Control de la enfermedad de Chagas. Segundo informe del comité de expertos de la OMS, OMS, Geneva, 120 pp.

Porcasi X, Hrellac H, Catalá S, Moreno M, Abrahan L, Hernández L, Gorla DE 2007. Infestation of rural houses by Triatoma infestans in the region of Los Llanos (La Rioja, Argentina). Mem Inst Oswaldo Cruz 102: 63-68.

Schofield CJ 1980. Nutritional status of domestic populations of Triatoma infestans. Trans R Soc Trop Med Hyg 74: 770-778.

Schofield CJ 1985. Population dynamics and control of Triatoma infestans. Ann Soc Belg Med Trop 65 (Suppl. 1): 149-164.

Schofield CJ 1994. Triatominae: Biología y control, Eurocommunica Publications, UK, 80 pp.

Schofield CJ, Lehane MJ, McEwen P, Catalá SS, Gorla DE 1992. Dispersive flight by Triatoma infestans under natural climatic conditions in Argentina. Med Vet Entomol 6: 51-56.

Schofield CJ, Matthews JN 1985. Theoretical approach to active dispersal and colonization of houses by Triatoma infestans. $J$ Trop Med Hyg 88: 211-222.

Schweigmann N, Vallvé S, Muscio O, Ghillini N, Alberti A, Wisnivesky-Colli C 1988. Dispersal flight by Triatoma infestans in an arid area of Argentina. Med Vet Entomol 2: 401-404.

Vazquez-Prokopec GM, Ceballos LA, Kitron U, Gürtler RE 2004. Active dispersal of natural populations of Triatoma infestans (Hemiptera: Reduviidae) in rural northwestern Argentina. J Med Entomol 41: 614-621.

Vazquez-Prokopec GM, Ceballos LA, Marcet PL, Cecere MC, Cardinal MV, Kitron U, Gürtler RE 2006. Seasonal variations in active dispersal of natural populations of Triatoma infestans in rural north-western Argentina. Med Vet Entomol 20: 273-279.

Williams NG, Schofield CJ 1985. The role of temperature in flight initiation of triatomine bugs. Trans R Soc Trop Med Hyg 79: 282.

Wisnivesky-Colli C, Gürtler RE, Solarz ND, Schweigmann NJ, Pietrokovsky SM, Alberti A, Flo J 1993. Dispersive flight and house invasion by Triatoma guasayana and Triatoma sordida in Argentina. Mem Inst Oswaldo Cruz 88: 27-32. 